\title{
PREMENSTRUAL SYNDROME IN NURSES
}

Aanal Bhoiwala , A Nimbalkar, Ajay Phatak, Somashekhar Nimbalkar

Department of Pediatrics, Pramukhswami Medical College, Karamsad, Gujarat, India. Pin -388325

Central Research Services, Charutar Arogya Mandal, Karamsad, Gujarat, India. Pin - 388325

Email: somu somu@yahoo.com. Phone: 9825087842

\section{Background and Aims:}

Premenstrual syndrome (PMS) is a condition which manifests with an array of predictable physical, emotional, cognitive, and behavioural symptom, that occur cyclically during the luteal phase of the menstrual cycle and resolve quickly at or within a few days of onset of menstruation. This study is being done in nurses because they are associated with much work in the hospitals even at night time which may have an impact on their work life.

Aim:. This study will allow us to estimate the prevalence and severity of PMS in nurses and identified probable associations of PMS and PMDD with age, locality, food habits, obesity, stress, genetic influence, menorrhagia and dysmenorrhoea.

\section{Methods:}

A cross-sectional observational study in which Premenstrual Symptoms Screening Tool for Adolescents (PSST-A) Questionnaire was selfadministered to screen PMS and Premenstrual Dysphoric Disorder (PMDD).

Interim analysis of 100 nurses from 1 centre is presented.

\begin{tabular}{|c|c|}
\hline $\begin{array}{c}\text { MENSTRUAL CYCLE } \\
\text { REGULARITY }\end{array}$ & \\
\hline Regular & 79 \\
\hline Irregular & 19 \\
\hline Others & 2 \\
\hline & \\
\hline LOCALITY & 51 \\
\hline Urban & 13 \\
\hline Semi urban & 30 \\
\hline Rural & 6 \\
\hline City slum & \\
\hline
\end{tabular}

\begin{tabular}{|l|r|}
\hline Junk food on regular \\
\hline NO & 29 \\
\hline YES & 71 \\
\hline & \\
\hline Stress & 37 \\
\hline NO & 62 \\
\hline YES & \\
\hline
\end{tabular}

Results:

$\checkmark$ The mean(SD) age of nursing students was 19.57(1.30) years.

$\checkmark$ Most students were Hindu(94), from urban/semi urban locality(70) and pursuing degree course(65).

$\checkmark 44$ had PMS while 31 had PMDD.

$\checkmark$ Albeit limited by sample size, the study could not found association of PMS with sociodemographic variables (locality, age, religion etc.), clinical features (BMI, severity of pain, regularity of menstruation etc.) or lifestyle (stress, consumption of junk food) [all $p>0.05$ ].

$\checkmark$ Not a single student screened positive was under treatment for the same.

$\checkmark$ The students screened positive for PMS/PMDD were referred to a gynaecologist for further management.

\section{Conclusion:}

Prevalence of PMS and PMDD in this population was quite high as compared to the same reported elsewhere.

Increasing awareness regarding PMS/PMDD along with support services to effectively manage it should be explored along with identifying factors associated with PMS/PMDD.

\begin{tabular}{|l|r|}
\hline EDUCATION & \\
\hline BSC & 64 \\
\hline GNM & 35 \\
\hline Diploma & 1 \\
\hline & \\
\hline RELIGION & 94 \\
\hline Hindu & 6 \\
\hline Christan & \\
\hline & \\
\hline MARITAL STATUS & 99 \\
\hline Single & 1 \\
\hline Married & \\
\hline
\end{tabular}

\begin{tabular}{|l|r|r|}
\hline & NO\% & YES \% \\
\hline $\begin{array}{l}\text { Complain of pain during } \\
\text { menstruation }\end{array}$ & 38.38 & 61.62 \\
\hline Family history & 98.98 & 1 \\
\hline Junk food & 29 & 71 \\
\hline Stresses & 37.37 & 62.63 \\
\hline PMDD & 69 & 31 \\
\hline PMS & 56 & 44 \\
\hline
\end{tabular}

